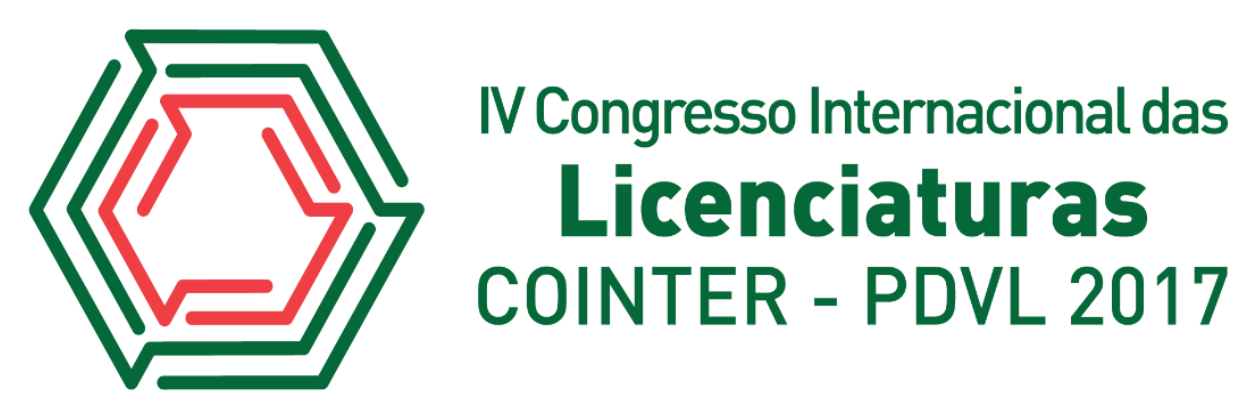

\title{
O PROCESSO DE ENSINO APRENDIZAGEM DOS NÚMEROS COMPLEXOS NO CENTRO ESTADUAL DE TEMPO INTEGRAL MARCOS PARENTE: UM ESTUDO EXPLORATÓRIO.
}

Apresentação: Pôster

\begin{abstract}
Ana Cristina de Sousa ${ }^{1}$; Givanildo Sales Silva²; Géssica Mayara Rocha de Carvalho ${ }^{3}$; Ronaldo Campelo da Costa ${ }^{4}$
\end{abstract}

\section{Introdução}

Os números complexos - também chamados de números imaginários - constituem um conjunto numérico mais amplo do que os números reais (INFOESCOLA, 2017). Eles surgiram por volta do século XVI, na Itália, quando alguns matemáticos, ao tentarem resolver equações do $2^{\circ}$ e $3^{\circ}$ grau, deparavam-se com raízes quadradas de números negativos $(\sqrt{-4}$, por exemplo) que não podem ser expressas no conjunto dos números reais. (CERRI E MONTEIRO, 2001).

Foi então que os matemáticos adotaram a denotação $i=\sqrt{-1}$ (que implica em $i^{2}=-1$ ), e o “ $i$ ” passou a ser conhecido como unidade imaginária (INFOESCOLA, 2017). Assim, as raízes quadradas de números negativos poderiam ser expressas a partir da unidade imaginária; veja:

$$
\sqrt{-4}=\sqrt{4 \cdot(-1)}=\sqrt{4} \cdot \sqrt{-1}=2 i
$$

Hoje sabe-se que a utilidade dos números complexos vai além da resolução das raízes quadradas de números negativos, podendo ser aplicados em áreas como a engenharia elétrica e de controle, o eletromagnetismo, a física quântica e a teoria do caos (CANDIDO et al, 2014).

Sendo assim, é importante que a abordagem das números complexos no ensino médio seja efetuada de forma a proporcionar ao aluno aprendizagem efetiva, podendo o educando utilizar este conhecimento como um instrumento para compreensão de mundo. Mas, na prática, como tem se efetivado o processo de ensino aprendizagem dos números complexos?

Pensado nisto, escolheu-se o tema desta pesquisa, cujo objetivo é compreender como se dá o

\footnotetext{
${ }^{1}$ Especialização em Ensino de Física, Instituto Federal do Piauí, anacristina.fisica@gmail.com

${ }^{2}$ Especialização em Ensino de Física, Instituto Federal do Piauí, nido10@hotmail.com

3 Especialização em Ensino de Física, Instituto Federal do Piauí, gessicamayararc@gmail.com

${ }^{4}$ Doutor, Instituto Federal do Piauí,ronaldocampelo@ifpi.edu.br
} 
processo de ensino aprendizagem dos números complexos no terceiro ano do ensino médio do Centro de Ensino de Tempo Integral - CETI - Marcos Parente. Acredita-se que os conteúdos referentes ao estudo dos números complexos não sejam vistos pelos alunos do ensino médio da forma desejada, embora sejam importantes para os educandos devido à suas aplicações.

\section{Fundamentação Teórica}

Sabendo das aplicações dos números complexos, o processo de ensino aprendizagem de tal assunto deve ser trabalhado de modo a viabilizar compreensão de tais aplicações pelo educando, já que a Lei de Diretrizes e Bases da Educação Nacional - LDB em seu atrigo 36, afirma que o currículo do ensino médio deverá destacar a compreensão do significado da ciência. Além disso, “Os conteúdos, as metodologias e as formas de avaliação serão organizados de tal forma que ao final do ensino médio o educando demonstre domínio dos princípios científicos e tecnológicos que presidem a produção moderna." (BRASIL, 1996).

Portanto, o processo de ensino aprendizagem não deve ser predominantemente abstrato, e baseado apenas em cálculos descarregados de sentido.

É necessário que o aluno do ensino médio veja os conteúdos estudados em sala de aula, não apenas como um conjunto de saberes acumulados e desconectados da sua realidade, mas sim como ferramentas para compreensão dos fenômenos presentes no seu mundo. Os Parâmetros Curriculares Nacionais - PCN's ainda nos declaram que os conhecimentos e as habilidades adquiridas pelo concludente do ensino médio devem lhes servir de "instrumentos reais de percepção, satisfação, interpretação, julgamento, atuação, desenvolvimento pessoal ou de aprendizado permanente" (PCN's, p.04).

Segundo Pietrocola et al (2000, apud SANTOS e FERRARA, p. 02), “os alunos não conseguem perceber a vinculação do conhecimento escolar com seu mundo vivencial”. Essa falta de relação com o dia a dia desmotiva os estudantes a durante o processo de ensino aprendizagem.

Então, caso o aluno saiba das aplicações dos números complexos, sua curiosidade poderá ser despertada, curiosidade esta que, segundo Paulo Freire em seu livro Pedagogia da Autonomia, é condição essencial e motivadora para o processo de ensino-aprendizagem. Segundo ele, a curiosidade "é que me faz perguntar, conhecer, atuar, mais perguntar, re-conhecer" é ela "que me move, me inquieta, me insere na busca, [sem ela] não aprendo nem ensino" (FREIRE, 1996). 


\section{Metodologia}

Para efetivação da proposta deste trabalho, fez-se uso de uma pesquisa exploratória, de natureza quantitativa. O campo da pesquisa foi o Centro Estadual de Tempo Integral - CETI - Marcos Parente, uma escola da cidade de Picos - PI, e os sujeitos da pesquisa foram vinte alunos do terceiro ano " $A$ " do ensino médio desta escola e seu respectivo professor de matemática.

$\mathrm{Na}$ coleta de dados, foi realizada uma entrevista com o professor de Matemática do CETI Marcos Parente na qual buscou-se identificar a metodologia utilizada no ensino dos números complexos e informar-se dos motivos que o levam à escolha de tal metodologia; Investigou-se também a opinião dos alunos com respeito a tal metodologia através de um questionário com perguntas objetivas do tipo "O que você acha da disciplina Matemática?" e "Qual das alternativas abaixo descreve melhor os números complexos?”.

\section{Resultados e Discussões}

O professor de Matemática no informou que a metodologia utilizada na quase totalidade das aulas era a tradicional, predominando sempre a resolução de cálculos. A justificativa para a escolha da metodologia era o pouco tempo disponível para a disciplina Matemática (250 minutos por semana) e a grande quantidade de conteúdo. Perguntamos se, durante as aulas, o professor separava um tempo para mostrar aos alunos as aplicações da disciplina na vivência dos alunos, e a resposta foi "não".

Quanto ao questionário feito aos alunos, algumas respostas são apresentadas a seguir em forma de gráfico:

Gráfico 1: O que você acha da disciplina Matemática? Fonte: Dados da Pesquisa

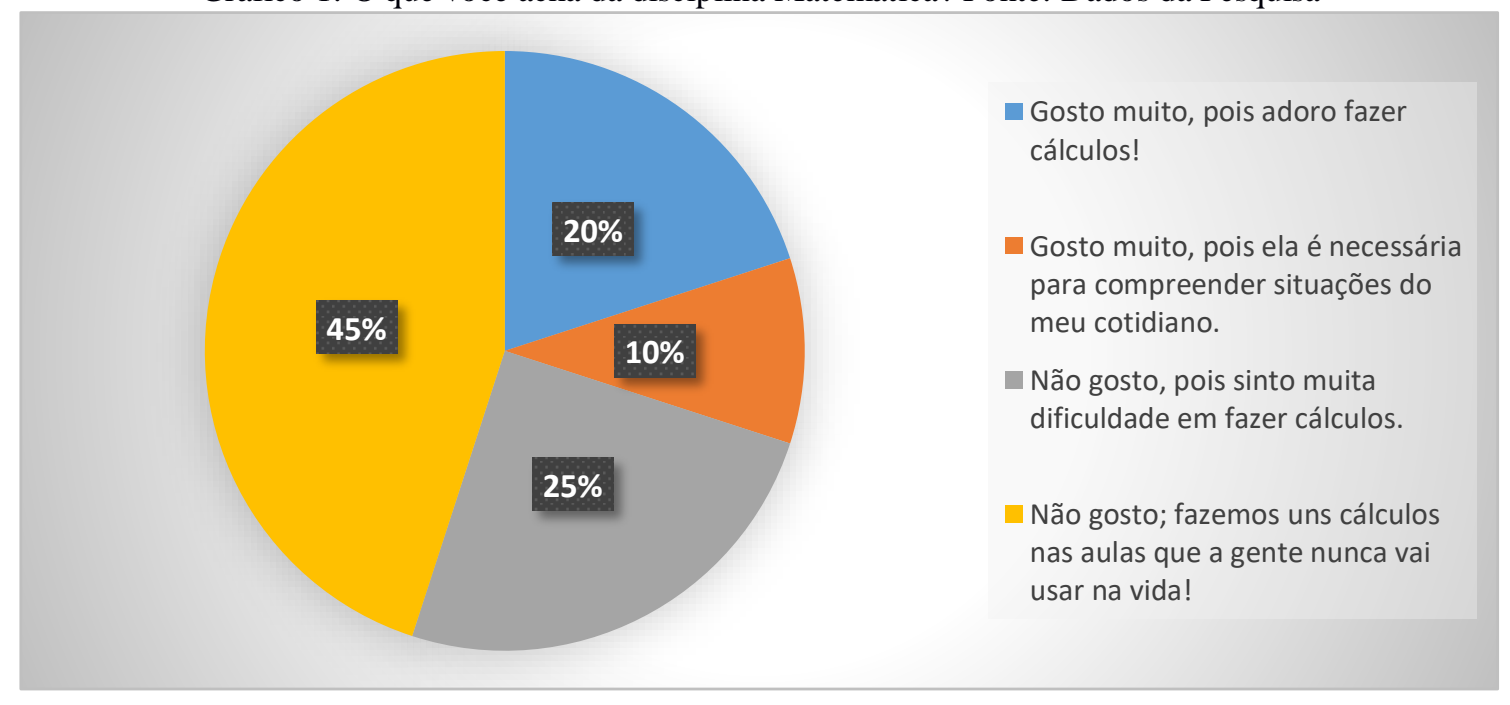


Gráfico 2: Qual das alternativas abaixo descreve melhor os números complexos? Fonte: Dados da Pesquisa

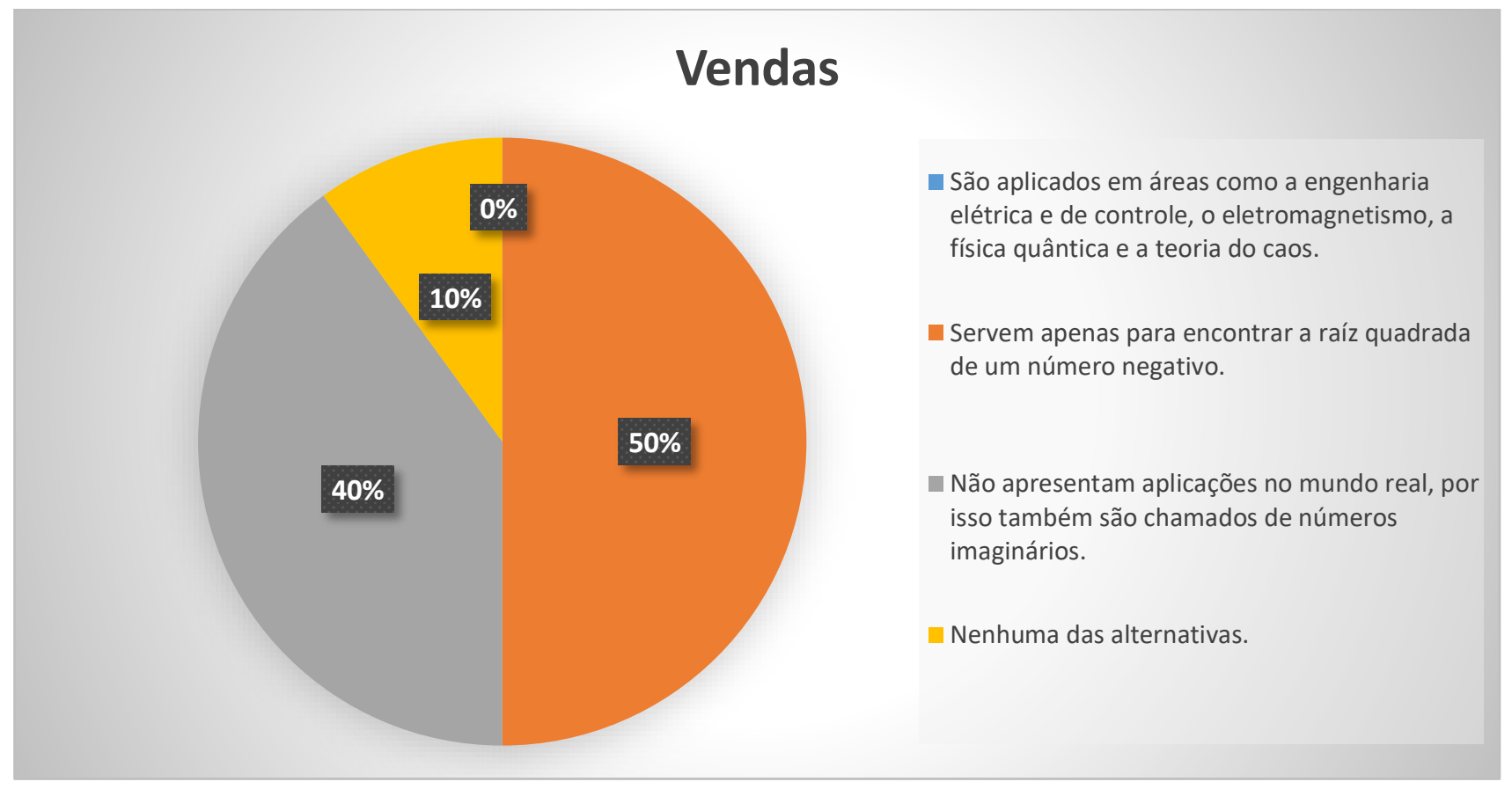

\section{Conclusões}

Os dados obtidos nesta pesquisa, principalmente as respostas dos alunos, mostram que o ensino dada Matemática no CETI Marcos Parente está desvinculado da vivência dos estudantes, sendo baseado principalmente na resolução de cálculos que na maioria das vezes não fazem sentido para os estudantes. Quanto ao estudo dos números complexos, percebe-se que os alunos não compreenderam sua utilidade para a ciência. Desta forma, os alunos sentem-se desmotivados no processo ensino aprendizagem.

É necessário, então, que a metodologia de ensino da Matemática - consequentemente dos números complexos - seja revista e reelaborada de forma a dar significado científico aos cálculos, atingindo assim os objetivos propostos pela legislação para o ensino médio.

\section{Referências}

BRASIL. Lei de Diretrizes e Bases da Educação Nacional - LDB Lei nº 9394/96.

BRASIL. Parâmetros curriculares nacionais do Ensino Médio: Parte III - Ciências da natureza, 
matemática e suas tecnologias. Ensino Médio. Brasília: MEC. 2000.

CANDIDO, A. C. P Outros Autores. Números Complexos. Universidade Estadual de Campinas UNICAMP, 2014.2 Disponível em: http://www.ime.unicamp.br/ ftorres/ENSINO/MONOGRAFIAS/NC2.pdf>. Acessado em 28 de setembro de 2017.

CERRI, C.; MONTEIRO, M. S.; História dos Números Complexos. Instituto de Matemática e Estatística da USP, 2001.

FREIRE, P. Pedagogia da autonomia: saberes necessários à prática educativa. - 29. ed. - São Paulo: Paz e Terra, 1996.

INFOESCOLA. Números Complexos. Disponível em: <http:// http://www.infoescola.com/matematica/numeros-complexos/>. Acessado em 28 de setembro de 2017.

SANTOS, R. V. C. dos; FERRARA, N. F.; Ondas eletromagnéticas e antenas: uma proposta de ensino através de atividades curtas multi-abordagem. Disponível em: <http://www.cienciamao.usp.br/dados/epef/_ondaseletromagneticasean.trabalho.pdf>. Acessado em 30 de setembro de 2017. 